Lima, Perú - 2019

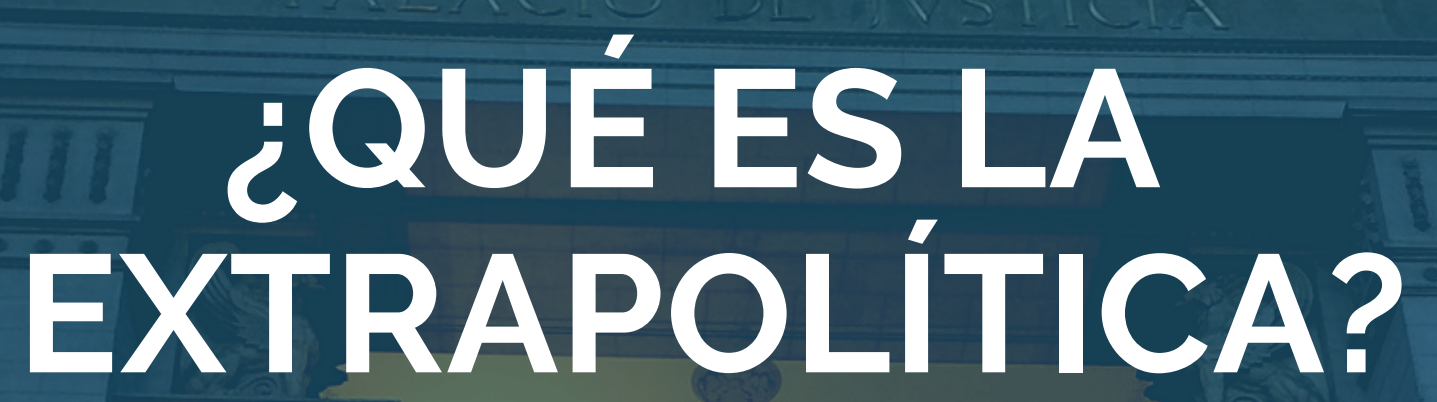

Pilares para la edificación de una política científica, tecnológica y transhumanista

$$
\begin{gathered}
\text { por } \\
\text { Piẹro Gayozzo }
\end{gathered}
$$

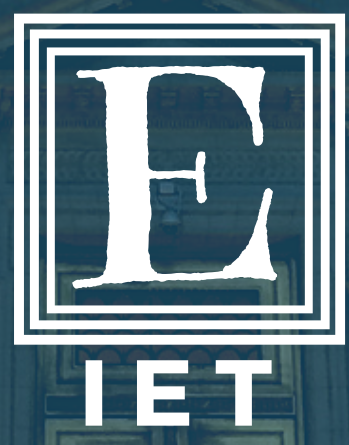

Instituto de Extrapolítica y Transhumanismo

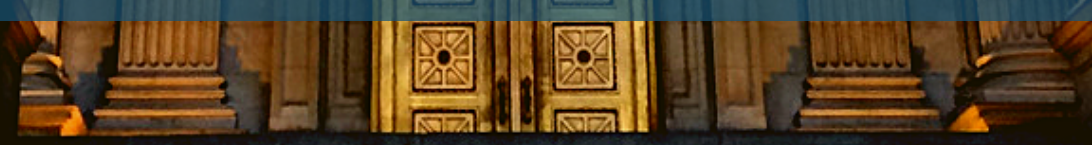




\title{
¿QUÉ ES LA EXTRAPOLÍTICA?
}

\author{
Pilares para la edificación de una política avanzada, científica, \\ tecnológica y transhumanista \\ por \\ Piero Gayozzo*
}

Parece ser que el tiempo que nos ha tocado vivir no tiene por rasgo característico la presencia de crisis políticas y sociales, pues siempre se han suscitado, sino la magnitud de estas. La militarización de los países, la amenaza que significan las armas nucleares y de destrucción masiva, la crisis ecológica, la tribalización y fragmentación del sentimiento humanista por visiones nacionalistas, la corrupción internacional y las guerras económicas son muestras de las proporciones del problema.

El caso peruano no es ajeno a la crisis internacional. La sombra de Odebrecht sigue empujando a los grandes actores políticos del país a la vez que se destapan escándalos de corrupción en diferentes instituciones del Estado. Procesos que ejercen evidentes efectos negativos en la sociedad (desatención del sistema de salud, precariedad educativa, etc.). En el escenario político solo existen partidos empresas, y en las aulas se siguen discutiendo las ideologías políticas clásicas que han demostrado su inacción o desidia, en el caso de la derecha dominante (Zapata, 2016), sus consecuencias nefastas e influencias sanguinarias, en el caso de la izquierda (Mariátegui, 2015), y su caducidad y falsedad, nacionalismo (Augusto, 2012).

A simple vista pareciera que poco pudiera hacerse; sin embargo, el desarrollo científico y tecnológico producto de la Era Digital en que vivimos y el consecuente cambio de paradigma que sus frutos nos ofrecen en esta llamada Cuarta Revolución Industrial (Schwab, 2016), nos brindan la posibilidad de proyectarnos hacia un mañana distinto en que la inteligencia artificial, la bigdata y la ingeniería genética cambiarán profundamente nuestras vidas y tendremos que tomar decisiones si queremos sobrepasarlas de la mejor manera (Giménez, 2017; Harari, 2016).

Ya varios autores han planteado la necesidad de que, para enfrentar dichos problemas y retos, la política se torne científica y universal, una política de la humanidad, lejos de los dogmas y de la política nacionalista (Bunge, 2012; León-Velarde, 2019; Morin, 2010; Harari, 2018). Por esta razón, y respondiendo a la manifiesta necesidad de replantear la organización estatal peruana (Amat y León Ch., 2012) es que para enfrentar estos nuevos retos sociales y tecnológicos surge la Extrapolítica. Se enarbola, así, como una propuesta para replantear la política en su esencia, su contenido y su práctica, con miras hacia la consecución de una Sociedad Avanzada, Científica, Tecnológica y Transhumanista.

En un trabajo anterior había esbozado la naturaleza de la Extrapolítica (Gayozzo, 2018). Ahora ofrezco a continuación los pilares sobre los que se edifica:

\section{Filosofía científica - Realismo Científico.}

En vista de la crisis que acompaña a la filosofía y sus escuelas de pensamiento (Bunge, 2002), la Extrapolítica procura un entendimiento objetivo y lo más certero posible de la realidad. Por ello se basa en la lógica para procurar coherencia interna; la semántica, para obtener una teoría realista del significado y del sentido; además de basarse en una ontología materialista (todo está formado por 
materia), dinámica (el cambio es constante), sistémica y emergentista (la realidad está formada por sistemas de los que emergen propiedades exclusivas); opta por una gnoseología realista, escéptica moderada, empirista moderada, racionalista moderada y científica. De esta manera adopta los requisitos para una filosofía científica denominada Realismo Científico (Bunge, 2011). Una vez dispuesta la interpretación de la realidad es posible adentrarse al conocimiento que esta propicia.

\section{Ciencia y Tecnología}

El conocimiento científico es aquella información estructurada, basada en la razón, sujeta a la experimentación y a la comprobación que sigue un método específico para definirse como tal. Su principal característica es que se opone al dogmatismo y se cimenta en la filosofía científica, pues le es propia. Es importante resaltar que no existe conocimiento científico subjetivo, la ciencia es universal y trasciende los idiomas, la cultura y supera los credos y la fe. Producto de su desarrollo se especializa y fundamenta la técnica, convirtiéndola en tecnología, la cual sirve como herramienta para superar la adversidad. Hacer Extrapolítica significa someterse a la evidencia antes de obrar y aceptar las bondades de la tecnología para desarrollar nuevos mecanismo de desarrollo social. Debido a que las tecnologías del siglo XXI son las conocidas como NBIC (nanotecnologías, biotecnologías, infotecnologías y cognotecnologías) y su alcance trasciende y trascenderá toda esfera social, compete a la extrapolítica garantizar una nueva estructura social en que se destaque el uso beneficioso de estas.

\section{Política Participativa y Científica}

Producto de los retos tecnológicos, existe la necesidad de que la política toma por bandera la ciencia y abandone las políticas ideologizadas de antaño (Gayozzo, 2018), pues el compromiso de la ciencia con la política es fundamental para el progreso de la sociedad. La política debe ser entendida, entonces, como la capacidad humana para crear sociedades a partir de acciones. Estas pueden ser diferenciadas en acciones cotidianas (política como hecho) y acciones estrictamente políticas como el gobierno de una localidad o la formación de partidos políticos (política stricto sensu). A la primera se le entiende como política participativa, pues reconocer que las acciones de un individuo repercuten en la sociedad es una manera de saber que la acción política depende en esencia también de los individuos antes que del Estado; no obstante, existen labores que solo pueden ejecutarse desde lo más alto de las Instituciones Estatales. Es así que hacer extrapolítica implica buscar el desarrollo de la sociedad en sus formas intelectuales, virtuosas y similares, siempre desarrollándolas en torno al conocimiento científico disponible, así como a través del desarrollo de proyectos particulares; y la agrupación de la comunidad científica para la difusión de un movimiento que pueda ocupar puestos gubernamentales.

\section{Humanismo Secular}

A la política le corresponde una ética, y evidentemente esta no debe responder a ideas Maquiavélicas (Bunge, 2012) porque si no desnaturalizaría y corrompería la vocación de servicio de la esencia política. Debe velar por la superación de las diferencias sociales (racismo, sexismo, homofobia, clasismo, etc.) y optar por la consecución de un nosotros diverso, integrador y globalizador (Degregori, 2014). Para ello, solo puede velarse por el respeto de los valores que bien comprende la ética humanista secular: competencia, igualdad, fraternidad, justicia, libertad y seguridad (Bunge, 2013). En resumida cuenta, adoptamos el principio bungeano para el humanismo "Goza la vida y ayuda a vivirla" sin prejuicios ni condenas dogmáticas (2012) como una de las aristas de la Extrapolítica. A ello le debemos agregar que, en vista de que las tecnologías orientadas desde un enfoque humanista sirven al desarrollo de la sociedad, el transhumanismo es una filosofía continuadora de su pensamiento (Gayozzo, 2019). Por ende, como parte del progreso, debe velarse por la superación de las limitaciones del hombre debido a que ser humanos es tratar de ser siempre mejores (Savulescu, 2005). 


\section{EXTRAPOLÍTICA}

De la relación existente entre filosofía y ciencia, tanto como de filosofía y política, y cómo esta última se basa en la ciencia, la cual requiere una ética y un manejo responsable que se extiende a todas sus dimensiones, es que no se trata de una relación lineal entre los monómeros ${ }^{1}$ de la Extrapolítica, sino de una interacción conjugada, una codependencia o una retroalimentación continua. Es de esta manera que la Extrapolítica $(\mathbb{E})$ respondería a una función como la siguiente:

$$
\mathbb{E}=A\left(F_{c} ; C_{T} ; P_{i} ; H^{+}\right)
$$

Donde,

La Extrapolítica $(\mathbb{E})$ sería una función dependiente de la acción $(A)$ basada en una Filosofía científica $\left(F_{C}\right)$, en Ciencia y tecnología $\left(C_{T}\right)$, en una Política integradora $\left(P_{i}\right)$ y en una ética Humanista avanzada - Transhumanismo $\left(H^{+}\right)$.

Conocida su naturaleza es posible entender su nombre, comprender que extra implica salir de la praxis política tradicional o realpolitik para dirigirnos hacia una Política Avanzada. Una política que revitalice la solidaridad, la convivencia, la ciencia, el secularismo y condene el armamentismo, el tribalismo, la división y los dogmas. Solo así será posible la consecución de una sociedad avanzada, de una sociedad en que nos hallemos como una misma especie en cooperación y solidaridad, en una Democracia Integral (Bunge, 2013) reestructurada utilizando tecnologías avanzadas.

Empero, en vista de que las ideologías son necesarias para el Estado y el desarrollo individual, además de ser inseparables de la vida cotidiana, la Extrapolítica, por sus pilares, es compatible con lo que Bunge propone y denomina como ideología científica $(2013 ; 2014)$. Por consiguiente, la Extrapolítica lejos de ser un dogma se convierte en la contraparte de las ideologías antihumanisticas, anticientíficas, irracionales y dogmáticas que se han desarrollado hasta ahora.

Hacer Extrapolítica, por lo tanto, implica obrar en torno a la evidencia científica y a los valores humanistas, buscando el bien de toda la humanidad y en armonía con el medio ambiente a través de la aplicación responsable de tecnologías avanzadas. La acción extrapolítica no se circunscribiría a la experimentación en laboratorios o a la comunidad científica únicamente, sino que abarca también la difusión, el estudio, la discusión y el debate sobre temas científicos y tecnológicos que cualquier persona o asociación pudiera realizar y promover, siempre que se ampare en los pilares descritos anteriormente. Su praxis implica velar por la formación de un movimiento social que busque la participación activa de la comunidad científica, e interesados, en el gobierno para garantizar y fomentar la secularización del Estado, la consecución de un Estado científico, la promoción de los valores humanistas, el desarrollo de una sociedad científica, el progreso de la especie humana y la evolución del modelo republicano hacia uno que aplique el adelanto tecnológico para crear nuevas instituciones para promover la evolución dirigida del hombre en pos de su bienestar individual y colectivo, tal cual lo ha venido haciendo desde su aparición en la tierra (García-Belaúnde, 2017).

\footnotetext{
${ }^{1}$ Un monómero es una molécula pequeña que al adherirse a otros de su misma clase forman una cadena más compleja denominada polímero.
} 
A modo de conclusión, la Extrapolítica surge como un modelo político para el mundo, cuya praxis es la de una política realista, política científica, política tecnológica, política transhumanista y política avanzada en conjunto, tal cual lo detalla el siguiente esquema:

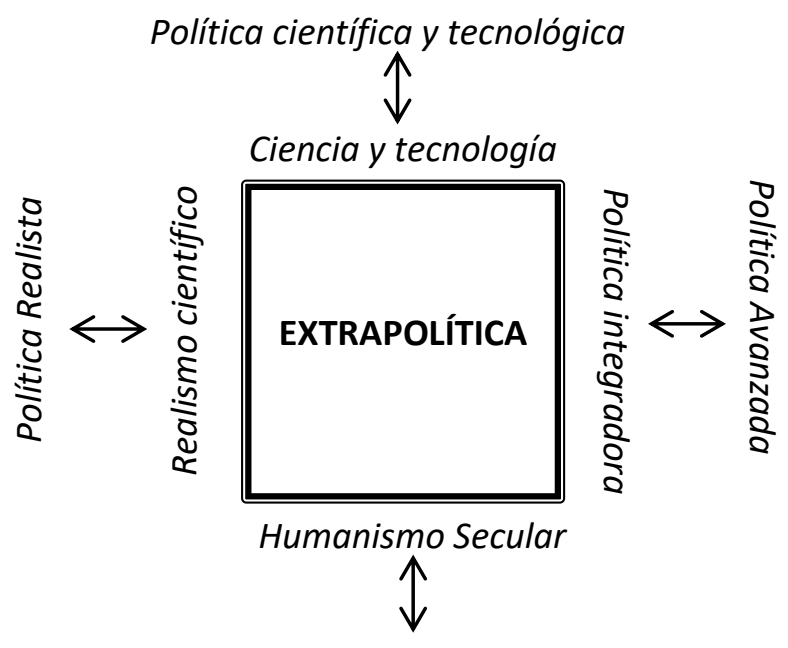

Política transhumanista

\section{Referencias Bibliográficas}

Amat y León Ch., C. (2012). El Perú nuestro de cada día. Lima: Universidad del Pacífico.

Augusto, R. (2012). El nacionalismo i Vaya timo! Navarra: Laetoli.

Bunge, M. (2002). Crisis y reconstrucción de la filosofía. España: Gedisa.

Bunge, M. (2011). Las Pseudociencias iVaya Timo! Barcelona: Laetoli.

Bunge, M. (2012). Filosofía de la tecnología y otros ensayos. Lima: Universidad Inca Garcilaso de la Vega.

Bunge, M. (2013). Filosofía Política. Solidaridad, cooperación y Democracia Integral. España: Gedisa.

Bunge, M. (2014). Ciencia, técnica y desarrollo. Pamplona: Laetoli.

Degregori, C. I. (2014). No hay país más diverso. Compendeio de antropología peruana (Vol. I). Lima: Instituto de Estudios Peruanos.

García-Belaúnde, V. (2017). La Genética de Dios. Lima: Máquina de Ideas.

Gayozzo, P. (2018). Teoría Extrapolítica y Postpoliticismo. . Lima: Instituto de Extrapolítica y Transhumanismo.

Gayozzo, P. (2019). Transhumanismo: Humanismo Avanzado. Lima: Instituto de Extrapolítica y Transhumanismo. Giménez, I. (2017). El futuro del trabajo y el trabajo del futuro. España: RBA.

Harari, Y. (2016). Homo Deus: Breve historia del mañana. Barcelona: Debate.

Harari, Y. (2018). 21 lecciones para el siglo XXI. Barcelona: Debate.

León-Velarde, F. (22 de Enero de 2019). El Comercio. Recuperado el 5 de Febrero de 2019, de https://elcomercio.pe/opinion/colaboradores/politica-publica-creencia-ciencia-fabiola-leon-velardenoticia-599851

Mariátegui, A. (2015). El octavo ensayo. Lima: Planeta.

Morin, E. (2010). ¿Hacia el abismo? Globalización en el siglo XXI. Barcelona: Paidós.

Savulescu, J. (2005). New breeds of humans: the moral obligation to enhance. Reproductive Biomedicine Online, 36-39.

Schwab, K. (2016). La Cuarta Revolución Industrial. Barcelona: Debate.

Zapata, A. (2016). Pensando a la derecha. Lima: Planeta. 